\title{
GERAKAN BERSIH LINGKUNGAN BERTEMA“GREEN ECO-PARK” SOLUSI TEPAT DALAM HIJAUKAN LINGKUNGAN KAMPUS FKIP UMPALEMBANG
}

\author{
Sapta Handaiyani1), Sri Wardhani'2), Ade Kartika ${ }^{3)}$ \\ 1), 2), 3) Program Studi Pendidikan Biologi Universitas Muhammadiyah Palembang \\ Jalan Jend. A. Yani 13 Ulu Palembang \\ Email: sapta.handaiyani@yahoo.com ${ }^{1}$, $\underline{\text { swwardhaniump@yahoo.com }}{ }^{2}$, adekartikakartika@yahoo.co.id $\left.^{3}\right)$
}

\begin{abstract}
ABSTRAK
Kegiatan Pengabdian kepada Masyarakat yang berjudul Gerakan Bersih Lingkungan Bertema "Green Eco-Park" Solusi Tepat dalam Hijaukan Lingkungan Kampus FKIP UM Palembang ini bertujuan untuk meningkatkan pengetahuan mahasiswa tentang menjaga lingkungan hidup agar tetap terjaga kebersihannya dan menciptakan kampus FKIP UMPalembang yang hijau dengan tema Green Eco-Park. Sehingga mahasiswa dapat bertanggung jawab terhadap lingkungan disekitarnya. Melalui kegiatan pengabdian masyarakat tentang Gerakan Bersih Lingkungan Bertema "Green Eco-Park" Solusi Tepat dalam Hijaukan Lingkungan Kampus FKIP UMPalembang diharapkan dapat menanamkan kepedulian, bertanggung jawab, dan kesadaran semua masyarakat kampus terutama mahasiswa dalam kebersihan lingkungan sekitar kampus. Khalayak dan sasaran dalam kegiatan pengabdian kepada masyarakat ini adalah mahasiswa semester VII kelas A Fakultas Keguruan dan Ilmu Pendidikan Program Studi Pendidikan Biologi. Mahasiswa yang terlibat berjumlah 45 orang mahasiswa dengan jumlah laki-laki 3 orang dan 42 perempuan. Kegiatan pengabdian kepada masyarakat ini dapat disimpulkan bahwa kegiatan ini membawa dampak positif bagi mahasiswa pendidikan biologi semester tujuh khususnya kelas $A$.
\end{abstract}

Kata kunci: Lingkungan, Green Eco-Park, UMPalembang

\section{PENDAHULUAN}

\subsection{Latar Belakang}

Kampus yang di dalamnya termasuk Mahasiswa, Dosen, Staf dan Karyawan memiliki peran penting dalam mewujudkan lingkungan kampus yang hijau, bersih, rapi, indah, dan sehat. Upaya yang telah dilakukan masyarakat kampus terhadap lingkungan sekitar kampus masih belum terlihat nyata antara lain sampah yang masih berceceran di halaman FKIP, sedikit kesulitan mencari kotak sampah, selokkan yang mulai dangkal, kebun Biologi yang masih banyak sisa penelitian dan belum banyak penghijauan disekitar kampus FKIP. Menurut UU No 32 (2009) bahwa lingkungan hidup adalah kesatuan ruang dengan semua benda, keadaan, dan makhluk hidup, termasuk manusia dan perilakunya yang mempengaruhi alam itu sendiri serta kelangsungan perikehidupan dan kesejahteraan manusia serta makhluk hidup lain. Perlindungan dan pengelolaan lingkungan hidup merupakan upaya yang terpadu dalam melestarikan fungsi lingkungan dan mencegah terjadinya pencemaran atau kerusakan lingkungan hidup. Lingkungan hidup dalam hal ini adalah lingungan hidup di kampus FKIP UM Palembang.

Lingkungan hidup yang seharusnya dikondisikan di lingkungan kampus ialah lingkungan yang asri, bersih serta nyaman untuk belajar. Hal ini dilakukan agar tumbuh semangat menciptakan lingkungan kampus yang bersih dan hijau dengan tema "Green Eco-Park". Kegiatan ini dilakukan dengan gotong royong mahasiswa Pendidikan Biologi Kelas VII.A yang berjumlah 45 orang dan dua orang Dosen Pendidikan Biologi dengan membersihkan selokkan halaman depan kampus, halaman belakang, Labolatorium, kebun Biologi, peletakkan kotak sampah dan penanaman tumbuh-tumbuhan buah di lingkungan kampus.

\subsection{Tujuan}

Kegiatan pengabdian masyarakat ini bertujuan untuk meningkatkan pengetahuan mahasiswa tentang menjaga lingkungan hidup agar tetap terjaga kebersihannya dan menciptakan kampus FKIP 
yang hijau dengan tema Green Eco-Park. Sehingga mahasiswa dapat bertanggung jawab terhadap lingkungan disekitarnya.

\subsection{Manfaat}

Manfaat yang diperoleh dari kegiatan ini adalah meningkatkan pengetahuan mahasiswa tentang menjaga lingkungan hidup agar tetap terjaga kebersihannya dan menciptakan kampus FKIP yang hijau dengan tema Green Eco-Park. Sehingga mahasiswa dapat bertanggung jawab terhadap lingkungan disekitarnya. Manfaat lainnya adalah lingkungan FKIP UMPalembang menjadi lebih tertata, sejuk dan nyaman sekaligus mendukung proses pembelajaran.

\subsection{Bentuk Kegiatan}

Beberapa kegiatan yang dilakukan dalam kegiatan ini adalah membersihkan saluran drainase, selasar, laboratorium, halaman parkir dan melakukan penghijauan di kebun biologi dan sekitar kolam FKIP UMPalembang.

\section{METODE PELAKSANAAN PENGABDIAN}

\subsection{Persiapan Pelaksanaan Pengabdian}

Persiapan yang baik akan memudahkan pelaksanaan kegiatan pengabdian ini yang melibatkan cukup banyak peserta dan menghindari kemungkinan terjadinya permasalahan saat pelaksanaan. Hal yang terkait dalam persiapan kegiatan ini adalah:

1) Melakukan diskusi tim pelaksana kegiatan pengabdian ini yang membahas terkait pembuatan proposal, tempat, waktu dan prosedur kegiatan.

2) Pembuatan proposal kegiatan pengabdian.

3) Pengajuan proposal kegiatan pengabdian kepada Lembaga Penelitian dan Pengabdian Masyarakat Universitas Muhammadiyah Palembang.

4) Pengajuan permohonan izin pada Dekan Fakultas Keguruan dan Ilmu Pendidikan Universitas Muhammadiyah Palembang tentang kegiatan pengabdian yang akan dilakukan.

5) Penandatanganan kontrak kegiatan antara ketua tim pelaksana dengan Lembaga Penelitian dan Pengabdian Masyarakat Universitas Muhammadiyah Palembang.

6) Pelaksanaan kegiatan.

7) Pembuatan laporan kegiatan.

\subsection{Peserta}

Peserta kegiatan gerakan bersih lingkungan kampus FKIP UMPalembang ini adalah mahasiswa semester VII kelas A Fakultas Keguruan dan Ilmu Pendidikan Program Studi Pendidikan Biologi. Mahasiswa yang terlibat berjumlah 45 orang mahasiswa dengan jumlah laki-laki 3 orang dan 42 perempuan.

\subsection{Waktu Kegiatan}

Kegiatan gerakan bersih dan penghijauan kampus ini dilaksanakan di Kampus FKIP Universitas Muhammadiyah Palembang selama 3 hari dalam waktu 3 minggu pada tanggal 9, 16 dan 23 November 2018 mulai dari pukul 07.00 - 11.00 WIB. Tempat atau lokasi sasaran kegiatan adalah FKIP, kolam ikan, kebun biologi, area parkir FKIP, laboratorium dan saluran drainase kampus.

\section{HASIL DAN PEMBAHASAN}

\subsection{Respon Mahasiswa}

Secara umum dapat dikatakan bahwa respon dan tanggapan mahasiswa terhadap kegiatan ini relatif baik. Adapun hal-hal yang mendukung argumentasi ini adalah:

a. Tingginya animo dan keinginan mahasiswa mengikuti kegiatan gotongroyong ini.

b. Mahasiswa antusias saat pelaksanaan kegiatan semua mahasiswa yang terlibat saling membantu untuk membuat lingkungan FKIP menjadi lebih bersih, rapi dan nyaman.

c. Mahasiswa mampu mengaplikasikan teori yang didapatnya di kelas pada matakuliah pengetahuan lingkungan. Sehingga mereka menjadi lebih paham. 


\subsection{Deskripsi Hasil Kegiatan}

Lingkungan kampus yang bersih sudah tentu menjadi dambaan seluruh warga kampus. Lingkungan kampus yang bersih akan sangat mendukung kenyamanan dan keberlangsungan proses belajarmengajar yang ada. Namun, sebagian warga kampus, termasuk mahasiswa, beranggapan bahwa menjaga kebersihan kampus adalah tugas para petugas kebersihan. Akibatnya sering ditemukan sampah berserahkan baik di dalam kelas, maupun di luar kelas serta kondisi lingkungan yang tanpa penghijauan juga menjadikan lingkungan semakin gersang. Bahkan yang lebih parah sampah-sampah tersebut menyebabkan saluran tersebut tersumbat sehingga jika musim hujan tiba dapat terjadi banjir. Oleh karena itu, perlu sekali menumbuhkan kesadaran kepada seluruh warga kampus bahwa kebersihan lingkungan kampus adalah tanggung jawab bersama, termasuk juga mahasiswa yang belajar di dalamnya.

Salah satu kegiatan yang dilakukan untuk menumbuhkan kesadaran dan kepedulian terhadap lingkungan pada diri mahasiswa UM Palembang yakni dengan melibatkan mahasiswa langsung dalam kegiatan pengabdian kepada masyarakat bertema gerakan bersih lingkungan dan juga penghijauan di sekitar lingkungan FKIP UMPalembang. Kegiatan ini juga merupakan implementasi dari mata kuliah pengetahuan lingkungan dan sebagai bentuk pendidikan lingkungan hidup kepada mahasiswa.

Kegiatan pengabdian berjudul Gerakan Bersih Lingkungan Bertema Green Eco-Park ini diadakan pada hari Jumat tanggal 9, 16 dan 23 November 2018. Kegiatan ini diikuti oleh beberapa dosen, pegawai, dan semua mahasiswa semester 7 kelas A tahun akademik 2018/2019. Kegiatan ini dimulai pukul 08.00 WIB - 11.00 WIB. Berdasarkan hasil identifikasi masalah, tempat atau lokasi sasaran kegiatan adalah FKIP, kolam ikan, kebun biologi, area parkir FKIP, laboratorium dan saluran drainase kampus seluruh area FKIP. Hal ini dikarenakan pada area tersebut ditemukan sampah-sampah yang berserahkan dan minimnya penghijauan.

Kegiatan bersih kampus diawali dengan menyuruh mahasiswa untuk membawa alat dan perlengkapan bersih-bersih, seperti sapu, sekop, kotak sampah, cangkul, ember, karung, dan alat lain yang diperlukan. Kemudian kegiatan ini dibuka dengan pengarahan oleh ketua pelaksana kegiatan untuk membagi area kerja. Kegiatan ini berlangsung dengan lancar tanpa halangan apapun. Semua dosen, pegawai, dan mahasiswa terutama tampak antusias membersihkan lingkungan kampusnya dari sampah-sampah yang berserahkan untuk hari pertama pada tanggal 9 November. Kegiatan ini dilanjutkan tanggal 16 dan 23 November yang ditambah dengan penanaman bunga dan tanaman buah disekitar pelataran dekat kolam FKIP dan kebun biologi. Terlebih lagi kegiatan ini dilakukan mahasiswa bersama-sama, selain menumbuhkan rasa kekeluargaan dan memupuk semangat gotong royong antar mahasiswa. Kebun biologi yang juga dirapikan kembali agar dapat dimanfaatkan sebagai sumber belajar. Sampah-sampah yang terkumpul dari seluruh area kerja tersebut kemudian dikumpulkan ditempat pembuangan sampah kampus untuk nantinya diangkut oleh mobil sampah dari dinas kebersihan kota Palembang.

Selain membersihkan lingkungan kampus, juga dilakukan penanaman tanaman buah dalam pot-pot besar yang diletakkan pada beberapa sudut kampus dan di kebun biologi. Diharapkan dengan ditanamnya tanaman bunga dan buah ini selain nantinya dapat membuat lingkungan kampus menjadi lebih asri, juga diharapkan dapat dimanfaatkan untuk kegiatan pembelajaran bagi mahasiswa program studi pendidikan biologi. Tak lupa juga dilakukan pemasangan papan himbauan untuk terus menjaga kebersihan lingkungan di seluruh lingkungan kampus.

Pada pukul 11.00 WIB dilakukan pengecekan untuk area kerja yang sudah dibersihkan. Hasilnya lingkungan kampus menjadi lebih bersih dari sebelumnya. Sampah-sampah di area FKIP sudah tidak terlihat lagi, saluran drainase kampus juga kembali mengalir, dan kebun biologi menjadi lebih rapi dan hijau dari sebelumnya. Jika kebersihan kampus terus dijaga maka lingkungan kampus menjadi semakin bersih, nyaman, dan terhindar dari banjir.

Pada akhirnya, kita semua berharap kegiatan pengabdian kepada masyarakat bertemakan Gerakan Bersih Lingkungan ini dapat bermanfaat bagi semua yang terlibat. Selain itu, kegiatan ini diharapkan dapat terus berlanjut hingga di waktu-waktu berikutnya. Karena untuk menumbuhkan kesadaran dan kepedulian terhadap lingkungan tidak dapat dijangkau dalam waktu yang singkat, perlu adanya pembiasaan dan kegiatan yang berkelanjutan untuk itu semua. 


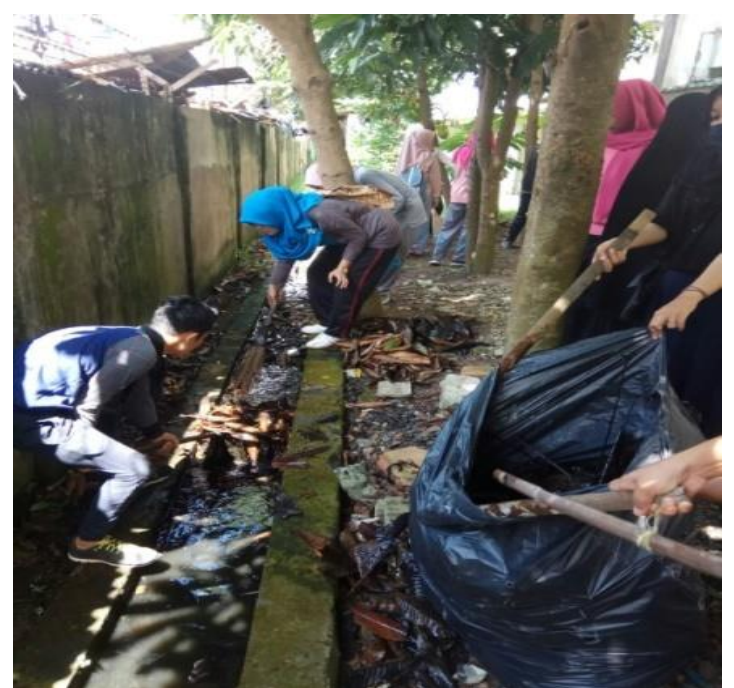

Gambar 1. Membersikan saluran drainase

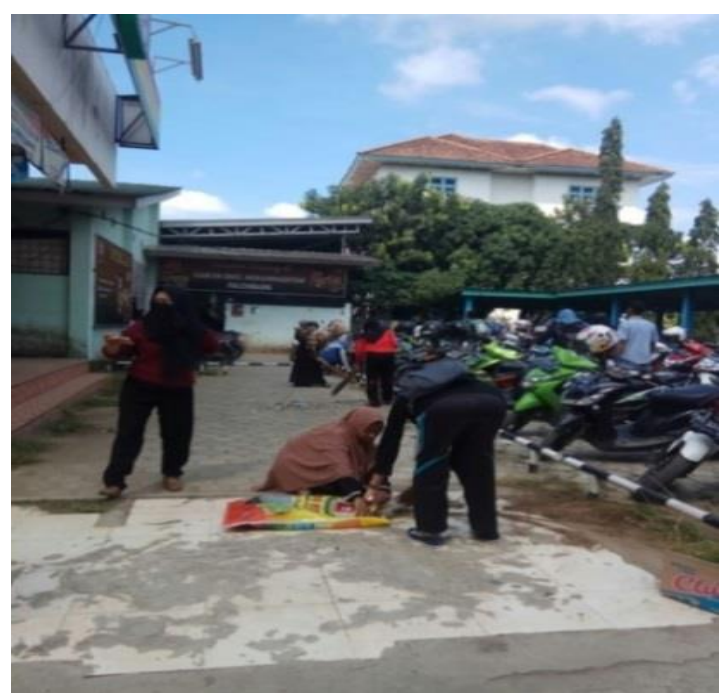

Gambar 3. Membersihkan halaman parkir

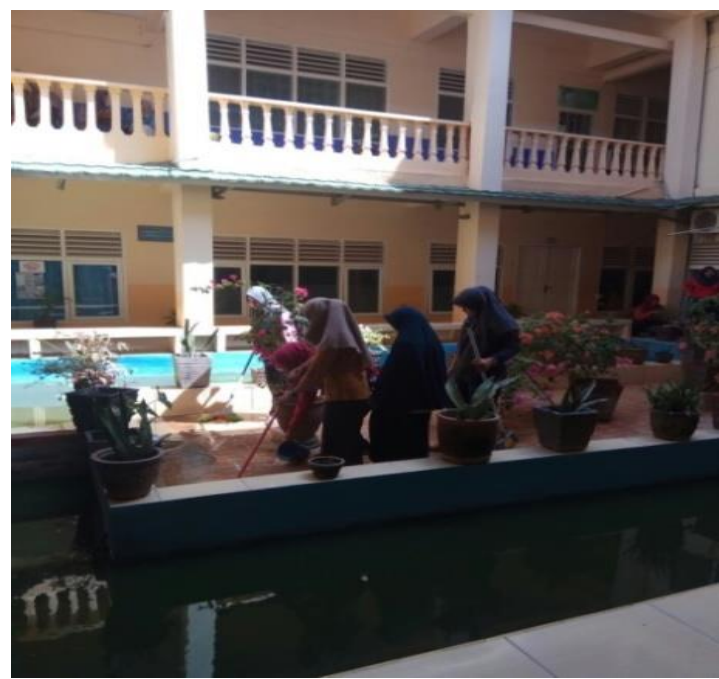

Gambar 5. Membersihkan selasar kolam biologi

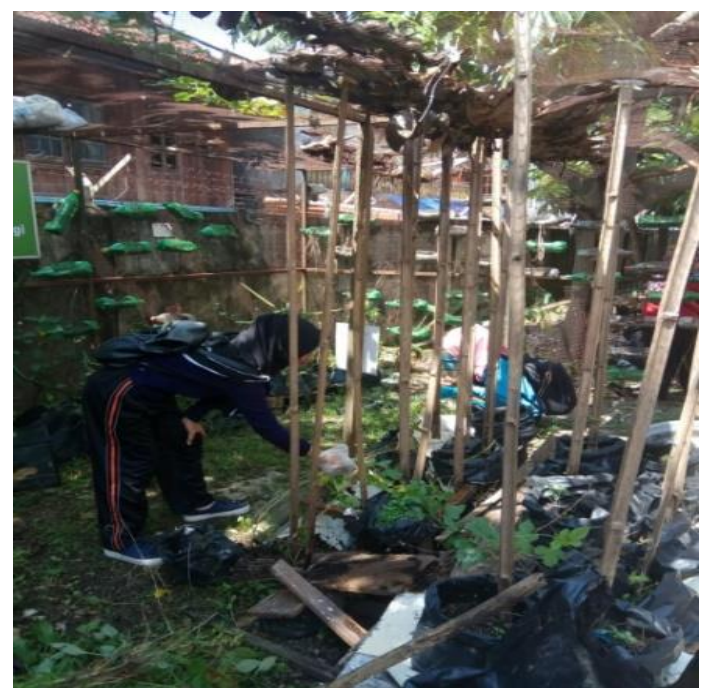

Gambar 2. Membersihkan kebun biologi

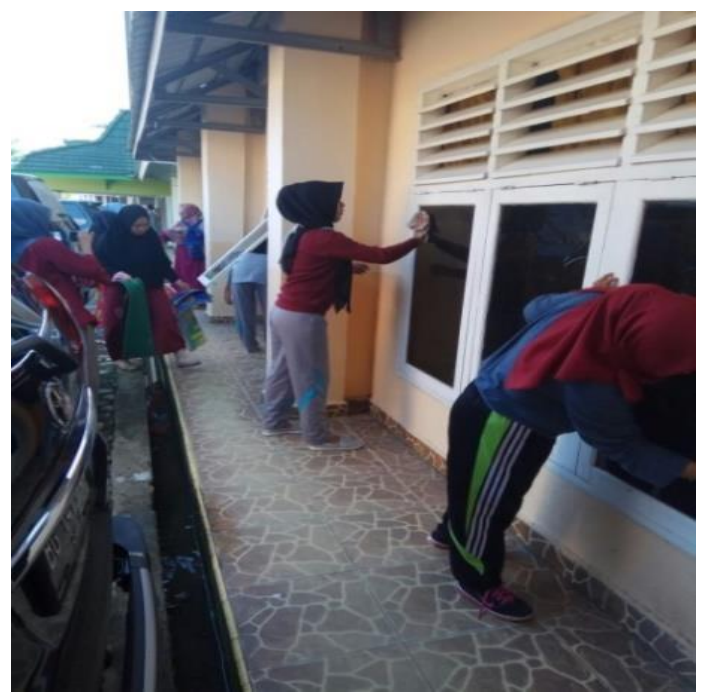

Gambar 4. Membersihkan laboratorium biologi

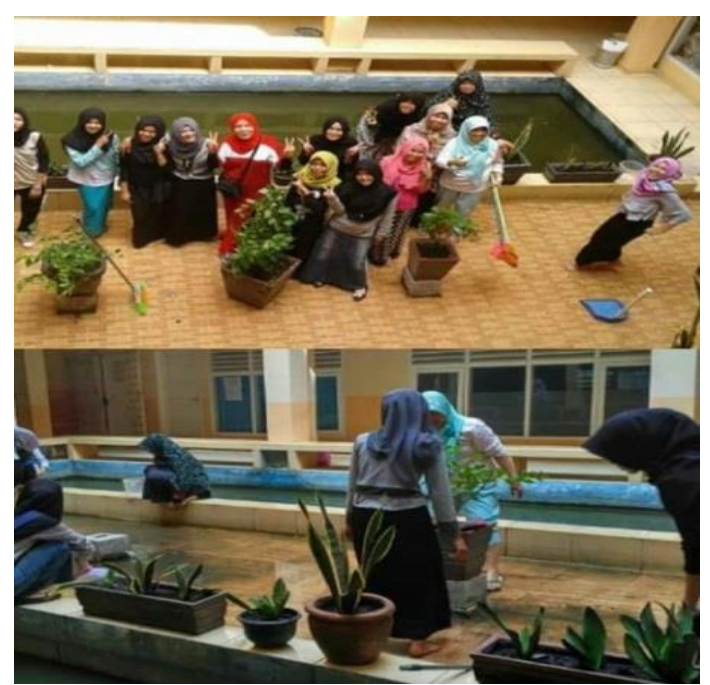

Gambar 6. Melakukan penghijauan dan penataan tanaman hias disekitar kolam 


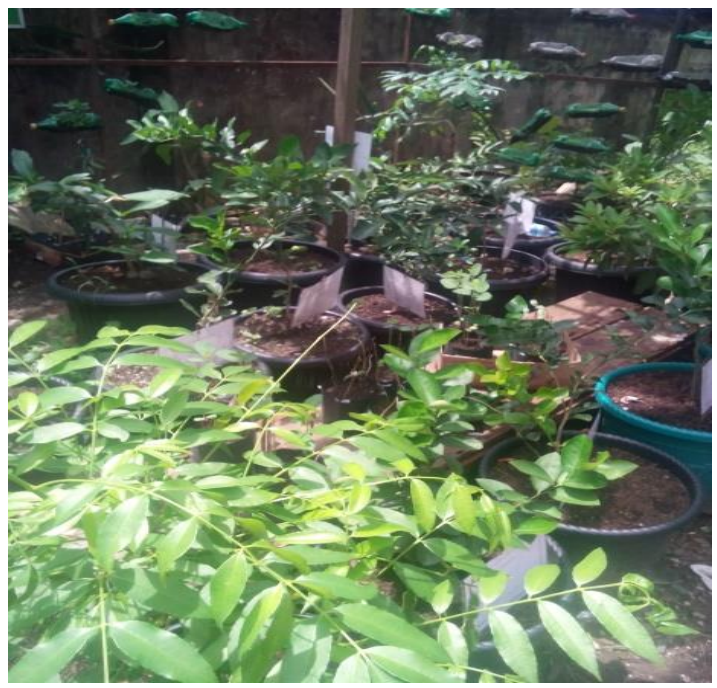

Gambar 7. Hasil penghijauan tanaman buah-buahan di kebun biologi

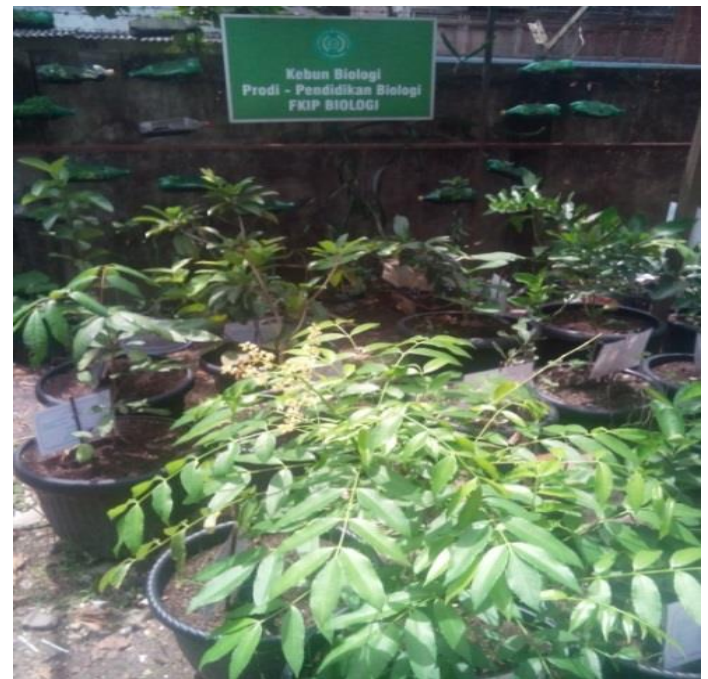

Gambar 8. Hasil penghijauan tanaman buah-buahan di kebun biologi

\section{KESIMPULAN}

Berdasarkan kegiatan pengabdian kepada masyarakat ini dapat disimpulkan bahwa kegiatan ini membawa dampak positif bagi mahasiswa pendidikan biologi semester tujuh khususnya kelas A. Kegiatan Gerakan Bersih Lingkungan Kampus bertema Green Eco-Park dengan melibatkan mahasiswa sebagai subjek utama adalah salah satu cara yang tepat untuk menumbuhkan rasa tanggung jawab atas kebersihan kampus. Sehingga mahasiswa akan selalu terdorong untuk menciptakan lingkungan kampus yang bersih dan nyaman untuk belajarnya.

\section{UCAPAN TERIMA KASIH}

Syukur Alhamdulillah penulis panjatkan kepada Allah SWT, atas rahmat dan karunia-Nya sehingga rangkaian kegiatan pengabdian ini dapat diselesaikan dengan baik. Kegiatan Pengabdian Kepada Masyarakat ini merupakan bagian dari Tri Dharma Perguruan Tinggi bagi setiap dosen. Semoga kegiatan pengabdian ini memberikan manfaat bagi kita semua.

\section{DAFTAR PUSTAKA}

Ananta, Aris. 1992. "Penduduk dan Pembangunan Berkelanjutan” dalam Warta Demografi Tahun XXII Nomor 9. September 1992. Jakarta : LD-FEUI.

Mantra, Ida Bagoes, 2000. Demografi Umum. Yogyakarta : Putaka Pelajar.

Republik Indonesia. 2009. Undang-Undang RI Nomor 32, Tahun 2009, tentang perlindungan dan pengelolaan lingkungan hidup. 